\title{
Orientação e formação do pesquisador No campo da educação
}

\author{
Luiza Helena Dalpiaz
}

RESUMO: No presente texto, meu objetivo é problematizar a orientação e mostrar particularidades do método com o qual trabalho no campo da educação. Esse método propicia condições para evidenciar problemas da formação do pesquisador, entre os quais se destaca como fundamental a elaboração do problema de pesquisa. Ao mesmo tempo, o próprio método contém uma metodologia para a construção do problema. E, de forma sucinta, mostro alguns efeitos do método na prática da orientação, considerando o processo formativo e a prática científica.

Palavras-chave: Prática de orientação. Formação do pesquisador. Prática de pesquisa. Análise institucional. Multirreferencialidade.

\section{The Orientation and Formation of the Researcher} In the area of Education

\begin{abstract}
In the present text, my objective is to problematize researcher orientation and show the particularities of the method with which I work in the field of education. This method demonstrates how to highlight problems in the researcher's training, among which the development of the research problem (to be researched) is fundamental. At the same time, the method itself contains a methodology for structuring the problem. And, briefly, I show some effects of the method in the practice of orientation, considering the formative process and the scientific practice.
\end{abstract}

* Doutora em Ciências da Educação pela Universidade Paris 8 é atualmente professora-pesquisadora no Programa de Pós-Graduação em Educação da Universidade do Oeste de Santa Catarina (UNOESC). É também pesquisadora associada do Centre de Recherche Interuniversitaire Expérience Ressources Culturelles Éducation. Joaçaba, SC- Brasil. E-mail: <luiza.dalpiaz@unoesc.edu.br>. 
Keywords: Orientation practices. formation of the researcher. Research practices. Institutional analysis. Multi-referenciality.

\section{Orientación y formación del investigador}

En el campo de la educación

RESUMEN: En este texto, mi objetivo es discutir la orientación y presentar las particularidades del método con el que trabajo en el campo de la educación. Este método permite evidenciar problemas en la formación del investigador, entre los cuales destaca como fundamental la elaboración del problema de investigación. Al mismo tiempo, el propio método incluye una metodología para construir el problema. Finalmente, de manera resumida, presento algunos efectos del método en la práctica de la orientación, considerando el proceso de formación y la práctica científica.

Palabras clave: Práctica de orientación. Formación del investigador. Práctica de investigación. Análisis institucional. Multirreferencialidad.

\section{Direction de recherche et formation du chercheur}

dans le domaine de l'éducation

RÉSUMÉ: Dans ce texte, mon objectif est de problématiser la direction de recherche et montrer les particularités de la méthode avec laquelle je travaille dans le domaine de l'éducation. Cette méthode fournit les conditions qui mettent en évidence les problèmes de formation du chercheur, parmi lesquels apparait comme fondamental l'élaboration du problème de la recherche. En même temps, la propre méthode contient une méthodologie pour la construction de problème. De manière succincte, je montre aussi certains effets de la méthode dans la pratique de la direction de recherche, en considérant le processus de formation et la pratique scientifique.

Mots-clés: Pratique de direction de recherche. Formation du chercheur. Pratique de recherche. Analyse institutionnelle. Multiréférentialité. 


\section{Introdução}

$\mathrm{N}$ o campo da educação, a orientação para a formação de pesquisadores na pós-graduação stricto sensu (mestrado e doutorado) se mostra um tema emergente no conjunto das pesquisas realizadas (BIANCHETTI, MACHADO, 2002). No entanto, como esses autores referem e observo em minha prática, a orientação tem uma função estruturante, pois se trata de um lugar que organiza um conjunto de elementos que constitui o ato de formar o pesquisador ${ }^{1}$ e produzir conhecimentos científicos. Ou seja, a orientação se constitui no "ponto nodal do sistema de pós-graduação" (SAVIANI, 2002, p.158).

O meu percurso acadêmico se caracteriza pela interface entre os campos do serviço social e da educação. Nesse caminho, o tema da formação de pesquisadores foi inicialmente abordado, do ponto de vista de orientanda, na tese de doutorado em ciências da educação, curso realizado no contexto francês. Nesse trabalho, elaborei a noção de crise do praticante para analisar particularidades do mal-estar vivenciado pelo assistente social em sua formação e prática profissionais e científicas, atravessadas por experiências de militância política.

A hipótese, então formulada, é de que a superação da crise supõe que o praticante se torne praticante-pesquisador sobre sua própria prática para produzir conhecimentos. Em consequência, subsídios são assim gerados tendo em vista potencialmente contribuir para (re)construção de projetos profissionais, organizacionais e científicos (DALPIAZ, 1994).

Na sequência, como orientadora, sistematizei um método para a orientação organizado a partir da noção de crise do praticante. O início dessa dinâmica se situa no triênio de avaliação 1996/1998, da Capes, com minha inserção como docente-pesquisadora em um Programa de Pós-Graduação em Serviço Social, em uma universidade privada, no semestre 1997/1. ${ }^{2}$ Na época, minha principal motivação residiu na possibilidade de participar da fundação de um curso de doutorado no referido Programa, o qual já contava com um curso de mestrado consolidado; ambos estiveram entre os primeiros a serem implantados no campo do serviço social, no Brasil.

Na década de 1990, a política de pós-graduação no Brasil estava condicionada a princípios neoliberais da gestão pública, entre os quais a "vinculação do financiamento aos índices de produtividade". Nesse contexto, acontecia um conjunto diversificado de mudanças, entre outras "a diminuição do tempo de certificação [...] a redefiniç̧ão do mestrado com o privilegiamento do doutorado, a vinculação de teses e dissertações a projetos de pesquisa institucional" (HOSTINS, 2006, p.143, 144).

No triênio 1996/1998, na Capes, se produzia uma ruptura em relação ao foco da política institucional, concernente ao aperfeiçoamento de pessoal para o ensino superior, com a "passagem da 'formação de professores' para a 'formação de pesquisadores"' (BIANCHETTI, 2011, p.444). Nesse mesmo triênio, também na Capes, foi instituído um 
novo modelo de avaliação acadêmica "que valoriza prioritariamente a produção científica e, portanto, a pesquisa" (KUENZER, MORAES, 2005, p. 1347).

Apesar do contexto favorável ao tema da formação de pesquisadores, o ingresso na pós-graduação como orientadora produziu dois problemas associados. Em primeiro lugar, uma tensão epistemológica, pois meu ponto de vista científico, formado no cenário acadêmico francês e no campo da educação, para além da simples repetição, ou da reprodução mecanicista, necessitava ser "traduzido" para tornar-se pertinente, considerando particularidades do campo do serviço social, no contexto profissional e acadêmico no Brasil.

Em segundo lugar, uma tensão política e organizacional, pois a construção de um programa de pesquisa, autoral e consistente, individual e coletivo, demanda um processo de trabalho e uma temporalidade opostos aos cânones do produtivismo. Esse é consequência da posição hegemônica atribuída aos procedimentos avaliativos de base quantitativista da produção acadêmica (KUENZER, MORAES, 2005).

Em tal contexto, em interstícios de uma trama feita paradoxalmente de determinismos conjunturais e de espaços singulares de autonomia (BIANCHETTI, 2011), fui construindo um rumo próprio para a formação de pesquisadores. Nesse caminho, em especial, a orientação se constituiu em um espaço privilegiado para resignificar lugares e práticas e produzir microrrupturas instituintes (DALPIAZ, DE LA FARE, 2000).

Esse trabalho, inicialmente realizado no campo do serviço social, desde 2013/2, está sendo (re)atualizado no campo da educação, a partir de minha inserção como docente-pesquisadora em um curso de mestrado em educação, de um programa de pós-graduação em educação, em uma universidade comunitária. Nesse contexto, a maior parte das pesquisas realizadas se referem à educação básica e aos profissionais da educação.

Neste texto, meu objetivo é problematizar a orientação e mostrar particularidades do método de orientação com o qual trabalho. O texto está organizado em dois seguimentos. No primeiro, exponho aspectos epistemológicos, teóricos e metodológicos que caracterizam o método. No segundo, aponto questões da formação de pesquisadores no campo da educação que emergem de minha prática singular como orientadora.

\section{Orientação e método para problematização de práticas profissionais}

Em termos etimológicos, a palavra orientação deriva de oriente, que significa: "'a parte onde nasce o sol' 'nascente, leste, levante”' (CUNHA, 1996, p.564). Em português, ao termo orientação são atribuídos, entre outros, os sentidos de "dispor de uma certa maneira, segundo a direção dos pontos cardeais; dirigir, encaminhar; informar; reconhecer o lugar em que se está (com relação à direção a seguir)”' (FERREIRA, 2017). 
A função do orientador é desencadear o desejo de conhecer no orientando, através de um caminho/método que promove a dúvida e a descoberta (MORIN, 1977, p.15-16; p.21-22). ${ }^{3}$ O objetivo é "ajudar a pensar por si mesmo" (MORIN, 1986, p.27), considerando o (re)conhecimento de uma filiação, ao mesmo tempo, epistemológica, teórica e metodológica (ARDOINO, 1993). Em outros termos, na perspectiva de Bourdieu (2001, p.21, 61), a orientação seria o lugar no qual o orientador estabelece condições práticas para que o orientando construa seu habitus científico, ou seja, se aproprie de um modus operandi e desenvolva uma "disposição incorporada" para a atividade racional, própria ao trabalho científico.

Método significa caminho, que se inspira em princípios a operacionalizar, e não se reduz a procedimentos formais a reproduzir ou a repetir. O método refere-se a um conjunto de ideias que estabelecem uma perspectiva e certas condições estratégicas, considerando-se a realização de um percurso para a produção de conhecimentos (MORIN, 1986). No plano teórico, o método com o qual trabalho na orientação tem como base uma tríade de referências indissociáveis.

A multirreferencialidade considera a hipótese da complexidade do real e propõe a leitura plural do problema/objeto de investigação, considerando pontos de vista distintos e heterogêneos. Esse trabalho exige cuidado e rigor epistemológicos para delimitar e articular diferentes saberes e conhecimentos, pertinentes e significativos, tendo em vista características próprias ao problema/objeto em pauta (ARDOINO, 1993).

A análise institucional socioanalítica indaga relações de poder e relações com o saber. A "análise em situação" trata de "[...] decifrar as relações que os indivíduos e os grupos mantêm com as instituições" (LOURAU, 1970, p. 267). Provoca, assim, a emergência do não saber (o invisível, o não dito, o oculto, o escotoma, o inconsciente) dos sujeitos implicados na situação analisada (AUTHIER; HESS, 1981). A instituição se constitui em campo de tensões entre forças instituídas (estabelecidas) e forças instituintes (transformadoras) do qual emerge a institucionalização (estabilização momentânea) da forma social (LOURAU, 1970).

O modelo de múltiplas trajetórias para a avaliação de políticas sociais coloca em relação fatos e discursos, traçando trajetórias de diferentes atores em diversos planos do tecido social na prática considerada. O objetivo é analisar narrativas singulares para identificar necessidades e demandas sociais, observar interações entre interlocutores, construir hipóteses de mudança e acompanhar o desenvolvimento e os efeitos de ações inovadoras (ZECCA, 1989).

Um ponto de convergência dessas três referências consiste na possibilidade para a produção de uma ruptura epistemológica, condicionada à mudança de lugar do sujeito que produz conhecimentos: o sujeito, individual ou coletivo, tradicionalmente dissociado do problema/objeto que investiga, passa a problematizar sua prática reconhecendo-se implicado na trama social que interroga. A implicação "é um nó de relações; não é 'boa' (uso 
voluntarista) nem 'má' (uso jurídico-policial) [...] [está] sempre já lá" (LOURAU, 1990, p.113), ou seja, trata-se de algo a analisar. O sujeito que analisa sua implicação considera a interação, relação e ação recíproca, entre sujeito-objeto-situação.

Para articular elementos desse conjunto de referências teóricas, trabalho com duas noções operativas - crise do praticante e tensão paradigmática. Dessa forma, estabeleço um princípio organizador do pensamento e um lugar singular a partir do qual o sujeito inicia o processo para a produção de conhecimentos.

Em seu sentido etimológico, o termo crise, do grego krísis significa "'alteração, desequilíbrio repentino' 'estado de dúvida e incerteza' 'tensão, conflito'"' (CUNHA, 1996, p.228). A crise instaura dúvidas, imprevisibilidade e abre um campo de possibilidades, com diferentes tendências: de transgressão e mudança; de (re)acomodação e retorno ao status quo; ou de agravamento da situação inicial. A noção de praticante refere-se ao sujeito que exerce sua prática, em diferentes campos de intervenção (social, educativo, político, terapêutico, científico etc.), em distintas instâncias organizacionais e institucionais.

A crise do praticante é constituída por três elementos entrecruzados e interdependentes: existencial (problemas de identidade profissional, individual e coletiva); político (dificuldades com relações de poder e nas relações com o saber) e científico (conflitos entre teoria e prática). A hipótese é de que a superação da crise supõe que o praticante se torne praticante-pesquisador sobre sua própria prática para produzir conhecimentos. Em consequência, subsídios são assim gerados tendo em vista potencialmente contribuir para a (re)construção de projetos profissionais, organizacionais e científicos (DALPIAZ, 1994).

A crise do praticante, inicialmente abordada como noção analítica do problema de pesquisa, se tornou uma noção epistemológica em minha prática científica (DALPIAZ; DE LA FARE, 2000). No começo da orientação, meu orientando é provocado a relatar seu percurso formativo e interventivo, assim como se interrogar sobre o caminho até então realizado, por meio de um instrumento chamado texto livre. ${ }^{4}$ Em consequência, o questionamento subjetivo, objetivado na escrita, estabelece "em ato" o lugar que instaura o "ponto de partida" do processo para produzir conhecimentos.

O praticante, ao se interrogar sobre sua própria prática, opera o princípio holográfico da complexidade: “[...] o todo está na parte que está no todo" (MORIN, 1986, p. 101). Esse princípio supõe que a pergunta do sujeito singular expressa um problema do respectivo campo de referência. A questão do sujeito caracteriza-se, ao mesmo tempo, como um indício, que sinaliza sentidos implícitos da prática (GINZBURG, 1989), e, em termos institucionais, como um analisador, pois permite "[...] revelar a estrutura da instituição, provocá-la, forçá-la a falar." (LOURAU, 1970, p. 283).

O trabalho do praticante para formular sua pergunta singular produz uma tensão paradigmática, ao desvelar a concomitância e o conflito entre tradições e exigências 
distintas que constituem o sujeito em sua prática, em diferentes instâncias organizacionais e institucionais (DALPIAZ; DE LA FARE, 2000).

A partir da articulação de elementos das referências teóricas anteriormente explicitadas, estabeleci um enunciado para o termo prática: trata-se de um tecido composto de elementos indissociáveis, múltiplos e heterogêneos, em interação, produzindo formas sociais, que se fazem e se desfazem sem parar, em um processo contínuo de institucionalização, no tensionamento entre forças instituídas e instituintes (DALPIAZ, 2002).

As duas noções operativas, crise do praticante e tensão paradigmática, particularizam o método para problematização de práticas profissionais. Esse método instaura condições para questionar percursos e situações, possibilitando, ao mesmo tempo, a emergência da pergunta do sujeito, em diferentes níveis complementares de complexidade. Tais condições são objetivadas em uma metodologia para a construção do problema da pesquisa (apresentada no próximo segmento), associada à formação de pesquisadores que emerge de minha prática singular como orientadora.

\section{Formação do pesquisador: problemas emergentes}

A noção de formação é utilizada na perspectiva da abordagem multirreferencial: partindo da hipótese do sujeito inacabado, o sujeito-autor de seu destino é sempre vir a ser, na emergência da pluralidade de si mesmo, na interação com a diversidade do mundo, na plasticidade de sua prática social. Segundo Ardoino (1977, p.242), a formação implica associação e complementaridade entre "o saber, o saber-fazer e o saber ser e vir a ser".

Minha prática como orientadora junto a estudantes de mestrado em serviço social teve início dois anos após ter finalizado o doutorado. Logo comecei a observar que mestrandos que eu orientava reproduziam dificuldades e formas de sofrimento que eu mesma havia vivenciado como orientanda. Na minha maneira de orientar, repetia ideias e procedimentos de meus mestres franceses. Assim, três perguntas a mim se impuseram: o que implica se constituir como orientadora? Qual é meu projeto para a orientação? Qual é a particularidade da formação no mestrado no Brasil ${ }^{5}$

Nós, orientadores, tínhamos tendência a "supor previamente nos orientandos um grau de autonomia, de discernimento e capacidade de identificação de problemas de pesquisa [...] que, normalmente, não é lícito esperar dos alunos, em especial no caso do mestrado" (SAVIANI, 2002, p.158-159).

De uma parte, porque o mestrado tem a função de "iniciação à formação do pesquisador" (SAVIANI, 2002, p.153). ${ }^{6}$ De outra parte, porque os mestrandos que eu orientava eram estudantes trabalhadores, e essa condição implicava duas questões epistemológicas: como construir um problema de pesquisa a partir da prática profissional? O que 
particulariza um problema de pesquisa que emerge da prática profissional em um mestrado acadêmico? ${ }^{7}$

Em decorrência desses questionamentos, juntamente com meus orientandos associei à minha prática de orientação duas funções complementares. Uma, de cunho investigativo, tendo em vista problematizar e desenvolver minha proposta para a orientação. Outra, de educação permanente, considerando a travessia a realizar para me tornar orientadora, além do papel administrativo (nos sentidos próprio e figurado do termo) que meu diploma de doutorado me autorizava a exercer. ${ }^{8} \mathrm{O}$ binômio investigativo/formativo como parte do trabalho de orientação se tornou um estilo que cultivo e aprimoro até hoje.

Nos termos da análise institucional socioanalítica, esse trabalho se caracteriza por um tipo de análise em situação (LOURAU, 1970), na qual minha própria prática como orientadora, suas particularidades e seus efeitos, se constituem objeto de análise individual e coletiva. $\mathrm{O}$ registro e a coleta de dados concernem a um conjunto diversificado de fontes: anotações pessoais sistemáticas dos encontros de orientação (individuais e coletivos), assim como das bancas de orientandos; textos escritos em coautoria entre orientadora e orientando(s), seja sobre o próprio processo investigativo/formativo, seja sobre tema associado; dissertações dos orientandos; textos individuais, publicados ou não, escritos pela orientadora. A análise de dados é feita "em ato", pois se constitui como parte da prática de orientação, ou seja, nos termos do trabalho socioanalítico o processo é produto (LOURAU, 1970, 1994).

O tripé conceitual que estrutura o eixo central de minha perspectiva científica e formativa é fruto de um processo de filiação intelectual a autores de referência, inicialmente construído em onze anos de trabalho na França. No entanto, em minha prática como orientadora, ao mesmo tempo em que procuro promover uma formação fundamentada em tais referências, constato várias dificuldades na prática do orientando, tais como:

» o enunciado da crise da ciência contemporânea pode levar o orientando a substituir o paradigma tido como "cartesiano/funcionalista" por um "novo" discurso, tornado um modismo acadêmico, reduzindo a ruptura paradigmática à reprodução de um pensamento linear e disjuntivo, assim como a repetição de procedimentos de pesquisa que se pretende superar;

» o princípio da análise da implicação do pesquisador pode conduzir o orientando a limitar o preceito da subjetividade na produção de conhecimentos científicos à expressão de sentimentos, ao relato de experiências, à prescrição ideológica, aos registros autobiográficos;

" a hipótese da complexidade e a proposta de leitura plural das práticas podem provocar dois tipos opostos de problemas para o orientando: uma paralisia, fruto do sentimento de impotência face à ideia da multiplicidade e heterogeneidade de 
referências a considerar; a ilusão de que é possível abordar a prática por meio da justaposição de diversos dados fragmentados;

» a análise em situação, da análise institucional socioanalítica, ao provocar a emergência do não saber do sujeito implicado na prática, pode causar desamparo e vazio no orientando, bloqueando, assim, possibilidades para a produção de conhecimentos.

Tais observações levam-me a interrogar sobre o problema da migração conceitual entre contextos linguísticos (da França para o Brasil) e entre áreas de conhecimento (da educação para o serviço social). A filiação ao autor de referência implica reconhecimento da origem do conceito e do vínculo que liga o sujeito ao genitor (autor) e à comunidade intelectual de origem (FERREIRA, 2017).

A migração supõe a "transferência de (dados e informações) [...] para outro lugar" (FERREIRA, 2017), geográfico e cultural. O deslocamento de um conceito produzido em determinado contexto exige tradução, ou seja, "passar (uma obra) de uma língua para outra" (FERREIRA, 2017); porém, para além do problema linguístico, têm que ser também consideradas as características e particularidades do novo ambiente.

Para Ardoino (1993, p.21), o autor é “o fundador, o criador, até mesmo o genitor, de toda forma, aquele que se situa, e que é explicitamente reconhecido por outros, como estando na origem de". Para Ardoino, a autoria supõe que o sujeito associe à criação, determinismos que co-operam na formulação do sujeito-autor.

A migração conceitual implica um trabalho de elucidação da origem e dos condicionamentos que constroem o conceito traduzido. Em outros termos, a migração conceitual supõe um processo constituído de três elementos: filiação - tradução - autoria. ${ }^{9}$ Esse processo organiza o trabalho epistemológico e formativo que, a meu ver, fundamenta o exercício de um pensamento multirreferencial. Em meu percurso, a diversidade de origens profissionais de meus orientandos (direito, educação física, enfermagem, medicina, pedagogia, psicologia, serviço social) aprofunda e fomenta tais interrogações. ${ }^{10}$

Em minha prática como orientadora, entendo que o problema principal da formação do pesquisador é a elaboração do problema de pesquisa. A experiência do praticante é complexa, pois constituída por uma multiplicidade de elementos em interação (psicológicos, sociais, econômicos, políticos, culturais etc.). Tais elementos se materializam em diferentes planos de intervenção, seguidamente entrelaçados (individuais, grupais, coletivos, organizacionais, comunitários etc.). O praticante é marcado pela cultura oral: há muito a contar, a comentar, a refletir. O praticante apresenta dificuldades para realizar a escrita acadêmica instituída, assim como na leitura e na interpretação de textos teóricos.

Minha hipótese para começar a orientação é de que o relato inicial do orientando expresso em uma escrita "espontânea", contém pistas, ainda que em filigrana, sobre elementos que compõem a pergunta do sujeito. O texto livre é um instrumento da orientação 
para trabalhar a análise da implicação do orientando, tendo em vista a elaboração do problema de pesquisa. ${ }^{11} \mathrm{O}$ texto livre estabelece uma objetivação discursiva - um texto escrito - para desencadear a interlocução entre orientadora e orientando. Ao mesmo tempo, esse texto suscita "em ato" a produção singular de conhecimentos pelo sujeito.

A prática do texto livre opera na alusão de objetos pré-construídos (BOURDIEU, 2001), ou seja, na abordagem do senso comum (empírico e conceitual) que habita o sujeito, e direciona tanto sua visão do mundo quanto sua representação da própria prática. Trata-se de uma produção textual individual, caracterizada por uma narrativa elaborada em termos próprios sobre situações vivenciadas, itinerários percorridos, observações realizadas, adversidades sofridas, tensões implícitas, questionamentos formulados.

Essa forma de escrita "livre" se constitui em instrumento para objetivação da experiência, possibilitando assim que o sujeito instaure uma distância entre o que está "dentro de si" e o que é colocado "para fora de si mesmo", através da escrita. Na orientação, instigo o orientando a se expressar sobre sua prática em questão, por meio de palavras e de expressões nas quais se reconhece. Assim sendo, a escrita cria condições para explicitar elementos de sua terminologia, assim como vestígios do fio condutor com o qual tece seu pensamento singular.

$\mathrm{Na}$ orientação, esse trabalho inaugura a metodologia para construção do problema de pesquisa constituída de três momentos distintos, aos quais correspondem respectivos instrumentos investigativos:

» explicitação do problema da prática: análise da implicação do sujeito em relação à sua prática profissional e/ou acadêmica e/ou militante. Instrumento: texto livre;

» formulação do problema teórico: a partir de questões emergentes do texto livre, elaboração de um mapa contextual/conceitual, formado pelas categorias constitutivas do problema da prática. Instrumentos: estudos bibliográficos e documentais; se for o caso, contatos e/ou entrevistas com pesquisadores e/ou outros profissionais com reconhecido saber sobre o problema em pauta;

» complexificação do problema empírico-teórico de pesquisa: realização da (re)formulação e estabelecimento de desdobramentos do problema de pesquisa. Instrumentos: interlocução com pares praticantes, aprofundamento de estudos bibliográficos e documentais.

Para além de uma aparente linearidade, os três momentos sinalizam rumos a explorar, que se entrecruzam e se influenciam mutuamente, na construção do caminho a ser percorrido pelo sujeito que produz conhecimentos. Essa metodologia materializa o método para problematização de práticas profissionais, o qual particulariza minha prática singular como orientadora. 


\section{Considerações finais}

No campo da educação, o tema da orientação se constitui em nó crucial da pósgraduação (stricto sensu). Simultaneamente, a formação à pesquisa se evidencia como necessária para a formação continuada, em particular, para profissionais da educação, praticantes que predominam no referido campo.

Neste texto, meu objetivo foi problematizar a orientação e mostrar particularidades do método com o qual trabalho. Esse método propicia condições para evidenciar problemas da formação do pesquisador, entre os quais aparece como fundamental a elaboração do problema de pesquisa. Ao mesmo tempo, o próprio método contém uma metodologia para a construção do problema. Tendo em vista limites formais do presente texto, apresento a seguir, de forma sucinta, alguns efeitos do método na prática da orientação. Tais efeitos sinalizam, a meu ver, para dois ângulos complementares e articulados entre si.

Do ponto de vista do processo formativo, a orientação cria condições para uma escuta singular do praticante, em espaço e temporalidade próprios (ARDOINO, 1993), no qual se exercita expressão individual, não julgamento do outro e reflexão compartilhada. Simultaneamente, se promove a experiência, sempre perturbadora e nunca finalizada, com a desconstrução de visões deterministas e pensamentos monorreferenciais. Essa forma de escuta é constituída pelo reconhecimento do trabalho vivo do sujeito (DEJOURS, 2009), o qual provoca a emergência de necessidades de conhecimento e do desejo de autoria (ARDOINO, 1993). Assim, a orientação propicia uma modificação no sentido do laço social entre orientadora e orientando: de uma relação centrada no controle da orientadora sobre a produção do orientando, para uma parceria entre dois interlocutores para a produção de conhecimentos, tanto individual quanto em coautoria (ZECCA, 1989).

Nesse contexto, do ponto de vista da prática científica, o orientando modifica a relação com o seu próprio saber e o conhecimento de autores de referência, ${ }^{12}$ estabelecendo distinções e articulações entre diferentes e complementares perspectivas da prática sobre a qual se interroga. Outro efeito a sinalizar é a diferenciação construída pelo orientando entre diversas formas da produção de conhecimentos que, tradicionalmente, estão confundidas e emaranhadas na problematização de práticas profissionais: questionamento existencial do sujeito, intervenção profissional do praticante, avaliação organizacional da ação e/ou da política, pesquisa científica sobre problema empírico-teórico emergente da prática.

Para finalizar, entendo oportuno mencionar ainda que esse trabalho, construído na interface dos campos do serviço social e da educação, se demonstra pertinente para outros campos profissionais. Essa afirmação tem como base minha experiência na orientação de mestrandos com diferentes formações na graduação, assim como experiências de interlocução e de intervenção junto a docentes e estudantes de outras áreas de conhecimento. 


\section{Recebido em 05/06/2017 e aprovado em 29/09/2017}

\section{Notas}

1 Considerando que neste texto, não problematizo questões de gênero, trabalho com uma escrita em termos genéricos e sem flexões.

2 A permanência no quadro docente do referido Programa reporta-se ao período de 1997/1 a 2003/1. As condições científicas, políticas e organizacionais que determinaram o término dessa experiência não se constituem em objeto de análise do presente artigo.

3 As traduções de textos do francês para o português foram por mim realizadas.

4 No próximo segmento apresentarei essa metodologia da orientação.

5 Por razões próprias à institucionalização da pós-graduação na França, no período em que lá residi e realizei minha formação, cursei o doutorado sem ter realizado previamente um mestrado, pois esse curso não existia na estrutura acadêmica da época.

6 Saviani (2002, p. 153-154) faz uma distinção que entendo fundamental para a prática docente, discernimento que fui construindo empiricamente no meu trabalho: "o vetor principal dos cursos de graduação é a formação profissional e não a formação de pesquisadores”. Em consequência, a iniciação científica na graduação "teria antes a finalidade de familiarizar o aluno (o futuro profissional) com os processos e os procedimentos da investigação científica".

7 Hostins (2006) mostra a tensão então presente no campo da pós-graduação entre as funções acadêmica e profissional, em um contexto marcado pelos preceitos neoliberais.

8 Bianchetti (2002, p. 172) comenta sobre o orientador: "é como se ele, tendo transposto o limiar da pósgraduação, tendo conseguido o grau de doutor, automaticamente alcançasse a qualificação para orientar. Num passe de mágica o orientando se transforma em orientador".

9 Essa hipótese está baseada em trabalho anteriormente realizado, com algumas modificações (DALPIAZ, DE LA FARE, 2000).

10 O trabalho que tenho realizado sobre o problema da migração conceitual se limita a uma problematização de minha prática como orientadora e como docente. Assim sendo, até o momento, não dirigi minha pesquisa para questões próprias aos campos da filosofia e da linguística, que compõem o problema.

11 A gênese do texto livre encontra-se em minha formação em ciências da educação, na Universidade Paris 8, especificamente, em trabalhos realizados com quatro professores que abordavam, em formas distintas, a análise da implicação do pesquisador pela prática da escrita: Michel Lobrot, com a escrita automática; René Barbier, com o diário de percurso; René Lourau, com o diário de pesquisa; Ruth Canter Kohn, interrogando motivações e objetivos do pesquisador para fazer pesquisa.

12 Dois procedimentos de pesquisa a destacar: estudo da polissemia de termos e o estudo "à letra" de textos de autores de referência, cuja inspiração é a forma de trabalhar (em aula, na escrita) de professores que tive durante minha formação em ciências da educação, na Universidade Paris 8: Jacques Ardoino e Guy Berger. 


\section{Referências}

ARDOINO, J. Éducation et politique; propos actuels sur l'éducation II. Paris: Gauthier-Villars, 1977.

L'approche multiréférentielle (plurielle) des situations éducatives et formatives. Pratiques de Formation - Analyses. Saint-Denis, n.25-26, p.15-41, avr. 1993.

AUTHIER, M.; HESS, R. L'analyse institutionnelle. Paris: PUF, 1981. (Que sais-je?, 1968)

BIANCHETTI, L. O desafio de escrever dissertações/teses: como incrementar a quantidade e manter a qualidade com menos tempo e menos recursos? In: BIANCHETTI, L.; MACHADO, A. M. N. (Orgs.) A bússola do escrever; desafios e estratégias na orientação de teses e dissertações. Florianópolis: UFSC; São Paulo: Cortez, 2002, p.165-185.

Condições de trabalho e repercussões pessoais e profissionais dos envolvidos com a pós-graduação stricto sensu: balanço e perspectivas. Linhas Críticas, Brasília, DF, v. 17, n. 34, p. 439-460, set./dez. 2011. Disponível em: <http://periodicos.unb.br/index.php/linhascriticas/article/ view/6239/5113>. Acesso em: 14 abr. 2017.

BIANCHETTI, L.; MACHADO, A. M. N. (Orgs.) A bússola do escrever; desafios e estratégias na orientação de teses e dissertações. Florianópolis: UFSC; São Paulo: Cortez, 2002.

BOURDIEU, P. O poder simbólico. Tradução de Fernando Tomaz. 4.ed. Rio de Janeiro: Bertrand Brasil, 2001.

CUNHA, A. G. Dicionário etimológico nova fronteira da língua portuguesa. 2.ed. rev. e acresc. de 124 p. 7 imp. Rio de Janeiro: Nova Fronteira, 1996.

DALPIAZ, L. H. Devenir praticien-chercheur, une possibilité pour le dépassement de la crise des travailleurs sociaux: l'approche d'une assistante sociale. 1994. Thèse (Doctorat en Sciences de l'Éducation), Département des Sciences de l'Éducation, Université Paris VIII - Vincennes à Saint-Denis, Saint-Denis-France, 1994.

Formação de pesquisadores e prática de orientação no Serviço Social. In: Encontro Nacional de Pesquisadores em Serviço Social, 8, 2002, Juiz de Fora. Anais. Juiz de Fora: ABEPSS, 2002. CD-ROM.

. Educação permanente e políticas públicas: problematização de práticas e produção de conhecimentos. Roteiro, Joaçaba, v.40, Edição Especial, p.173-192, 2015.

DALPIAZ, L. H.; DA LA FARE, M. Multiforme: Filiation... traduction... trahison... autorisation... Élements d'un projet "en acte" et d'une pratique singulière d'institutionnalisation d'un groupe de recherché au Brésil. In: Colloque International de l'Association Francophone Internationale de Recherche Scientifique en Éducation - "L'universel et le singulier; l'éducation comme dialectique: experiences et recherche", IX, 2000, Rennes, France. Actes. Rennes, France: AFIRSE, Université Rennes 2, Haute Bretagne, 2000, p.224-229.

DEJOURS, C. Travail vivant 2: Travail et émancipation. Paris: Payot, 2009.

FERREIRA, A. B. H. Dicionário do Aurélio, 2017.

GINZBURG, C. Mitos, emblemas, sinais: morfologia e história. Tradução Federico Carotti. São Paulo: Companhia das Letras, 1989.

HOSTINS, R. C. L. Os Planos Nacionais de Pós-Graduação (PNPG) e suas repercussões na pósgraduação brasileira. Perspectiva, Florianópolis, v. 24, n. 1, p. 133-160, jan/jun. 2006. Disponível em: $<$ http://www.perspectiva.ufsc.br>. Acesso em: 14 abr. 2017. 
KUENZER, A. Z.; MORAES, M. C. M. Temas e tramas na pós-graduação em educação. Educ. Soc., Campinas, vol. 26, n. 93, p. 1341-1362, set./dez. 2005.

LOURAU, R. L'analyse institutionnelle. Paris: Minuit, 1970. (Arguments)

Implication et surimplication. Revue du Mauss. Paris, n.10, p.110-120, 4. trim. 1990.

MORIN, E. La méthode 1. La nature de la nature. Paris: Seuil, 1977. (Points, Essais, 123)

La méthode 3. La connaissance de la connaissance. Paris: Seuil, 1986. (Points, Essais, 236)

SAVIANI, D. A pós-graduação em educação no Brasil: pensando o problema da orientação. In:

BIANCHETTI, L.; MACHADO, A. M. N. (Orgs.) A bússola do escrever; desafios e estratégias na orientação de teses e dissertações. Florianópolis: UFSC; São Paulo: Cortez, 2002, p.135-163.

ZECCA, M. L'évaluation: outils d'émancipation? In: BACHMANN, C. Les savoirs-faire de l'inquiètude et du renouveau: une formation à l'évaluation de l'action sociale. Paris: PROMOFAF, 1989, p.57-59. 